Article

\title{
Evaluation of Ascorbic Acid or Curcumin Formulated in a Solid Dispersion on Salmonella Enteritidis Infection and Intestinal Integrity in Broiler Chickens
}

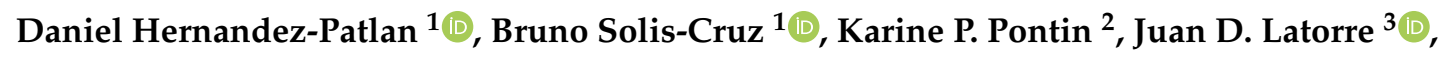 \\ Xochitl Hernandez-Velasco ${ }^{4}$, Ruben Merino-Guzman ${ }^{4}{ }^{(0)}$, Abraham Mendez-Albores ${ }^{5}{ }^{\circ}$, \\ Billy M. Hargis ${ }^{3}$, Raquel Lopez-Arellano ${ }^{1}$ and Guillermo Tellez-Isaias ${ }^{3, *(D)}$ \\ 1 Laboratorio 5, LEDEFAR, Unidad de Investigacion Multidisciplinaria, Facultad de Estudios Superiores (FES) \\ Cuautitlan, Universidad Nacional Autonoma de Mexico (UNAM), Cuautitlan Izcalli 54714, Mexico; \\ danielpatlan@comunidad.unam.mx (D.H.-P.); brunosc@comunidad.unam.mx (B.S.-C.); \\ rlajjd@yahoo.com.mx (R.L.-A.) \\ 2 Departamento de Medicina Veterinária Preventiva, Centro de Diagnóstico e Pesquisa em Patologia Aviária, \\ Universidade Federal do Rio Grande do Sul, Porto Alegre RS 97105-900, Brazil; pontin.karine@gmail.com \\ 3 Department of Poultry Science, University of Arkansas, Fayetteville, AR 72704, USA; \\ juandlatorre@gmail.com (J.D.L.); bhargis@uark.edu (B.M.H.) \\ 4 Departamento de Medicina y Zootecnia de Aves, Facultad de Medicina Veterinaria y Zootecnia, UNAM, \\ Ciudad de Mexico 04510, Mexico; xochitl_h@yahoo.com (X.H.-V.); onirem@unam.mx (R.M.-G.) \\ 5 Laboratorio 14, Alimentos, Micotoxinas y Micotoxicosis, Unidad de Investigacion Multidisciplinaria, \\ FES Cuautitlan, UNAM, Cuautitlan Izcalli 54714, Mexico; albores@unam.mx \\ * Correspondence: gtellez@uark.edu
}

Received: 26 October 2019; Accepted: 8 November 2019; Published: 10 November 2019

\begin{abstract}
Two experimental models were conducted to evaluate and compare the effect of ascorbic acid (AA) or curcumin formulated in a solid dispersion (SD-CUR) as prophylactic or therapeutic alternatives to prevent or control $S$. Enteritidis (SE) infection in broiler chickens. In the prophylactic model, dietary administration of AA showed a significant reduction in SE counts in crop compared to the positive control (PC) group $(p<0.05)$, whereas in cecal tonsils (CT), SD-CUR significantly reduced SE recovery. Superoxide dismutase (SOD) activity was significantly higher in chickens supplemented with AA or SD-CUR, and total intestinal IgA levels were significantly lower in both treatments when compared to the PC group. Serum fluorescein isothiocyanate-dextran (FITC-d) levels were reduced by SD-CUR compared to PC, while AA presented significantly lower total aerobic bacteria. In the therapeutic model, only the dietary administration of AA significantly decreased SE in crop and CT on days 3 and 10 post-challenge. FITC-d levels were significantly lower in both treated groups in comparison to PC, but IgA levels were significantly reduced only by AA. The results suggest that dietary AA and SD-CUR have different modes of action to reduce SE intestinal colonization in two different challenge models in broiler chickens.
\end{abstract}

Keywords: Ascorbic acid; curcumin; chickens; Salmonella Enteritidis; intestinal integrity

\section{Introduction}

The restriction of antibiotics at subtherapeutic doses in animal production as growth promoters has been associated with increased bacterial infections in poultry and, paradoxically, greater use of antibiotics [1-6]. Therefore, interest in finding viable alternatives with similar benefits to antibiotics has increased in recent years [7], mainly to prevent, control, and treat infections associated with Salmonella, a foodborne pathogen that remains a significant concern in public health [8]. In recent years, the 
investigation of alternatives to antibiotics has been focused on improving intestinal health through the use of feed additives such as probiotics, prebiotics, in-feed enzymes, essential oils, herbal extracts, and antioxidants [9].

In poultry production, antioxidants are included in diets primarily to protect feed from degradation and deterioration during storage, as well as for nutritional purposes [10]. However, it has been reported that these additives play an essential role in the prevention of several diseases in poultry due to their different mechanisms of action [11].

Ascorbic acid (AA) is a water-soluble organic compound with potent antioxidant properties due to its ability to readily donate electrons to protect the host from oxidative stress [12,13]. Furthermore, AA has an immunomodulatory effect and can improve the microbial diversity and function $[13,14]$. Dietary supplementation with AA has shown to promote positive effects in reducing the physiological stress caused by the rapid growth rate and the ever-changing environmental conditions in poultry production [15].

Meanwhile, Curcumin, a polyphenolic compound derived from turmeric, a product of the plant Curcuma longa [16], has been widely used in the poultry industry as an anticoccidial, anti-inflammatory, immunomodulatory, antimicrobial, antioxidant, and to promote growth performance [17-19]. Nevertheless, some limitations of curcumin are its poor aqueous solubility and intestinal permeability [20]. Due to these limitations, the preparation of solid dispersions of curcumin (SD-CUR) has managed to increase both the solubility and permeability of curcumin given the fact that the crystalline structure changes to an amorphous form [21]. Therefore, in the present study, two natural antioxidants such as AA and SD-CUR were evaluated as prophylactic or therapeutic alternatives to prevent or control $S$. Enteritidis infection and help to maintain healthy intestinal integrity in broiler chickens.

\section{Results}

Results of the dietary administration of AA and SD-CUR at $0.1 \%$ in the feed as prophylactic agents on $S$. Enteritidis counts are shown in Table 1 . In both independent trials, $S$. Enteritidis counts in crop were statistically 1.2 log lower in the AA group compared to the PC group $(p<0.05)$, whereas in CT, chickens supplemented with SD-CUR presented significantly lower $S$. Enteritidis counts and $S$. Enteritidis incidence $(p<0.05)$ in comparison with the PC group. Furthermore, SOD activity was significantly higher in chickens supplemented with AA and SD-CUR in comparison with the PC group, whereas total intestinal IgA levels were significantly lower in the AA and SD-CUR groups compared to the PC group (Table 2). However, serum FITC-d levels were only significantly lower in the SD-CUR group when compared to the PC group (Table 2). Finally, TAB were significantly reduced in chickens treated with AA compared to the other two experimental groups, but chickens treated with SD-CUR tended to increase the counts of TAB $(P=0.07)$ compared to the animals consuming the control unsupplemented diet (PC).

Table 3 shows the bacterial counts and incidence of $S$. Enteritidis after 3 and 10 days of treatment with AA and SD-CUR at $0.1 \%$ inclusion in the feed post-S. Enteritidis challenge (therapeutic model). On day three post-S. Enteritidis challenge, $S$. Enteritidis counts in the crop, and CT significantly decreased by $2.05 \mathrm{log}$ and $3.54 \mathrm{log}$ in the AA in relation to control, resulting in a significant decrease in the incidence of $S$. Enteritidis in both crop $(p<0.01)$ and CT $(p<0.005)$. Interestingly, although not significant, $S$. Enteritidis counts in the crop and CT were reduced by $1.02 \log$ and $1.59 \log$ in the SD-CUR group compared to the PC group. Meanwhile, on day 10 post-S. Enteritidis challenge, although the $S$. Enteritidis counts in crop were significantly lower in the AA and SD-CUR groups when compared to the PC group, only the AA group significantly decreased the $S$. Enteritidis counts in CT by $4.71 \mathrm{log}$, as well as the incidence of $S$. Enteritidis $(p<0.001)$. Furthermore, serum FITC-d levels were significantly lower in AA and SD-CUR groups in comparison with the PC group (Table 4). However, only total intestinal IgA levels were statistically lower in the AA group compared to the PC group. Finally, no significant differences in SOD activity were found among the experimental groups (Table 4). 
Table 1. Salmonella Enteritidis (SE) counts ${ }^{1}$ and incidence ${ }^{3}$ in crop and cecal tonsils (CT) in broiler chickens supplemented with ascorbic acid (AA) and a solid dispersion of curcumin (SD-CUR). Prophylactic model ${ }^{2}$.

\begin{tabular}{ccccc}
\hline Treatments & Crop $\log _{\mathbf{1 0}} \mathbf{~ c f u / g}$ & Crop + / - (\%) ${ }^{3}$ & CT $\log _{\mathbf{1 0}} \mathbf{c f u} / \mathbf{g}$ & CT + / - (\%) \\
\hline \multicolumn{5}{c}{ Trial 1 } \\
\cline { 2 - 5 } Ctrl & $2.68 \pm 0.47^{\mathrm{ab}}$ & $9 / 12(75 \%)$ & $4.01 \pm 0.29^{\mathrm{a}}$ & $12 / 12(100 \%)$ \\
AA & $1.48 \pm 0.53^{\mathrm{b}}$ & $5 / 12(42 \%)$ & $3.69 \pm 0.17^{\mathrm{a}}$ & $12 / 12(100 \%)$ \\
SD-CU & $3.08 \pm 0.57^{\mathrm{a}}$ & $9 / 12(75 \%)$ & $2.42 \pm 0.54^{\mathrm{b}}$ & $8 / 12(67 \%)^{*}$ \\
\hline \multicolumn{5}{c}{ Trial 2 } \\
Ctrl & $2.69 \pm 0.48^{\mathrm{a}}$ & $9 / 12(75 \%)$ & $3.94 \pm 0.22^{\mathrm{a}}$ & $12 / 12(100 \%)$ \\
AA & $1.49 \pm 0.54^{\mathrm{b}}$ & $5 / 12(42 \%)$ & $3.80 \pm 0.28^{\mathrm{ab}}$ & $12 / 12(100 \%)$ \\
SD-CUR & $3.19 \pm 0.47^{\mathrm{a}}$ & $9 / 12(75 \%)$ & $2.34 \pm 0.50^{\mathrm{b}}$ & $8 / 12(67 \%)^{*}$ \\
\hline
\end{tabular}

${ }^{1}$ Data expressed in $\log _{10} \mathrm{cfu} / \mathrm{g}$ of tissue. Mean \pm standard error from 12 chickens $(p<0.05) .{ }^{2}$ Chickens were orally gavaged with $10^{7} \mathrm{cfu}$ of $S$. Enteritidis per chicken at 6-d old, samples were collected $24 \mathrm{~h}$ later. ${ }^{3}$ Data expressed as positive/total chickens $(\%) .{ }^{*} p<0.05$. ${ }^{a-b}$ Values within treatment columns for each treatment with different superscripts differ significantly $(p<0.05)$.

Table 2. Determination of total aerobic bacteria (TAB), serum fluorescein isothiocyanate-dextran (FITC-d) levels, superoxide dismutase (SOD) activity and total intestinal IgA levels in broiler chickens treated with ascorbic acid (AA) and a solid dispersion of curcumin (SD-CUR) in the prophylactic model (Trial 2) ${ }^{1}$.

\begin{tabular}{ccccc}
\hline Treatments & TAB $\log _{\mathbf{1 0}} \mathbf{c f u} / \mathbf{g}$ & FITC-d $(\mu \mathrm{g} / \mathrm{mL})$ & SOD $(\mathbf{U} / \mathbf{m L})$ & IgA $(\mu \mathrm{g} / \mathbf{m L})$ \\
\hline Ctrl & $7.96 \pm 0.10^{\mathrm{ab}}$ & $0.591 \pm 0.055^{\mathrm{a}}$ & $3.58 \pm 0.31^{\mathrm{b}}$ & $14.21 \pm 0.83^{\mathrm{a}}$ \\
AA & $7.92 \pm 0.11^{\mathrm{b}}$ & $0.533 \pm 0.034^{\mathrm{ab}}$ & $4.50 \pm 0.35^{\mathrm{a}}$ & $11.51 \pm 0.71^{\mathrm{b}}$ \\
SD-CUR & $8.27 \pm 0.13^{\mathrm{a}}$ & $0.432 \pm 0.037^{\mathrm{b}}$ & $4.48 \pm 0.20^{\mathrm{a}}$ & $11.20 \pm 0.53^{\mathrm{b}}$ \\
\hline
\end{tabular}

${ }^{1}$ Data are presented as mean \pm standard error from 12 chickens $(p<0.05) .{ }^{\mathrm{a}-\mathrm{b}}$ Values within treatment columns for each treatment with different superscripts differ significantly $(p<0.05)$.

Table 3. Salmonella Enteritidis (SE) counts ${ }^{1}$ and incidence ${ }^{3}$ in crop and cecal-tonsils (CT) in broiler chickens supplemented with ascorbic acid (AA) and a solid dispersion of curcumin (SD-CUR) in the therapeutic model ${ }^{2}$.

\begin{tabular}{|c|c|c|c|c|}
\hline Treatments & Crop $\log _{10} \mathrm{cfu} / \mathrm{g}$ & Crop + / - (\%) & CT $\log _{10} \mathrm{cfu} / \mathrm{g}$ & $\mathrm{CT}+/-(\%)$ \\
\hline & \multicolumn{4}{|c|}{ 3-d post-S. Enteritidis Challenge } \\
\hline Ctrl & $3.18 \pm 0.46^{\mathrm{a}}$ & $10 / 12(83 \%)$ & $6.44 \pm 0.15^{\mathrm{a}}$ & $12 / 12(100 \%)$ \\
\hline AA & $1.13 \pm 0.48^{b}$ & $4 / 12(33 \%) *$ & $2.90 \pm 0.91^{b}$ & $6 / 12(50 \%) * *$ \\
\hline \multirow[t]{2}{*}{ SD-CUR } & $2.16 \pm 0.46^{\mathrm{ab}}$ & $8 / 12(67 \%)$ & $4.85 \pm 0.86^{\mathrm{ab}}$ & $9 / 12(75 \%)$ \\
\hline & \multicolumn{4}{|c|}{ 10-d post- $S$. Enteritidis Challenge } \\
\hline Ctrl & $2.93 \pm 0.65^{a}$ & $7 / 12(58 \%)$ & $6.61 \pm 0.21^{\mathrm{a}}$ & $12 / 12(100 \%)$ \\
\hline AA & $1.26 \pm 0.54^{b}$ & $4 / 12(33 \%)$ & $1.89 \pm 0.81^{b}$ & $4 / 12(33 \%) \varphi$ \\
\hline SD-CUR & $0.97 \pm 0.51^{b}$ & $3 / 12(25 \%)$ & $4.81 \pm 0.85^{\mathrm{ab}}$ & $9 / 12(75 \%)$ \\
\hline
\end{tabular}

${ }^{1}$ Data expressed in $\log _{10} \mathrm{cfu} / \mathrm{g}$ of tissue. Mean \pm standard error from 12 chickens $(p<0.05) .{ }^{2}$ Chickens were orally gavaged with $10^{7} \mathrm{cfu}$ of $S$. Enteritidis per chicken at 6-d old, samples were collected $24 \mathrm{~h}$ later. ${ }^{3}$ Data expressed as positive/total chickens (\%). ${ }^{*} p<0.01 ;{ }^{* *} p<0.005 ; \varphi p<0.001$. ${ }^{\mathrm{a}-\mathrm{b}}$ Values within treatment columns for each treatment with different superscripts differ significantly $(p<0.05)$. 
Table 4. Determination of serum fluorescein isothiocyanate-dextran (FITC-d) levels, superoxide dismutase (SOD) activity and total intestinal IgA levels in broiler chickens supplemented with ascorbic acid (AA) and a solid dispersion of curcumin (SD-CUR). Therapeutic model (day 10 post-S. Enteritidis challenge) ${ }^{1}$.

\begin{tabular}{cccc}
\hline Treatments & FITC-d $(\mu \mathrm{g} / \mathrm{mL})$ & SOD $(\mathrm{U} / \mathrm{mL})$ & $\operatorname{IgA}(\mu \mathrm{g} / \mathrm{mL})$ \\
\hline Ctrl & $0.700 \pm 0.020^{\mathrm{a}}$ & $10.34 \pm 0.67^{\mathrm{a}}$ & $14.34 \pm 2.81^{\mathrm{a}}$ \\
AA & $0.457 \pm 0.039^{\mathrm{b}}$ & $10.22 \pm 0.72^{\mathrm{a}}$ & $9.18 \pm 2.95^{\mathrm{b}}$ \\
SD-CUR & $0.489 \pm 0.020^{\mathrm{b}}$ & $9.72 \pm 0.82^{\mathrm{a}}$ & $11.26 \pm 3.39^{\mathrm{ab}}$ \\
\hline
\end{tabular}

${ }^{1}$ Data are presented as mean \pm standard error from 12 chickens $(p<0.05) .{ }^{\text {a-b }}$ Values within treatment columns for each treatment with different superscripts differ significantly $(p<0.05)$.

\section{Discussion}

The production of antibiotic-free poultry is a worldwide trend [22] derived from the restriction of the use of antibiotics as a measure to reduce the problems of bacterial resistance and maintain the safety of food [6]. However, this measurement has increased the incidence of bacterial infections [2]. Therefore, the interest in finding viable alternatives with similar benefits to antibiotics has increased in recent years [7], mainly to reduce bacterial resistance problems, improve or maintain performance parameters, and control foodborne pathogens such as Salmonella [8].

Dietary AA supplementation into the feed at $0.1 \%$ in the prophylactic model (Table 1 ) proved to be more effective in reducing the $S$. Enteritidis counts in the crop than in the CT, in both trials. This is due to the capability of AA, a weak acid ( $\mathrm{pKa}=4.1$ and 11.6), to reduce the $\mathrm{pH}$ in the crop by the release of protons $[23,24]$. However, as AA begins to degrade as the $\mathrm{pH}$ increases [25], its acidifying capacity is affected, as well as its influence on the stimulation of growth of beneficial bacteria like Lactobacillus and Bifidobacterium [26]. Therefore, these results support our findings in CT and agree with other published studies in which supplementation with $1 \% \mathrm{AA}$ in the feed had no effect reducing the intestinal $\mathrm{pH}$ of broilers $[27,28]$. In contrast, supplementation with SD-CUR significantly reduced $S$. Enteritidis counts in CT by $>1.5 \log$ in both independent trials (Table 1). This reduction is related to the increase in the solubility and permeability of curcumin when formulated in a solid dispersion using PVP-K30 [29,30] and, therefore to the improvement of its antimicrobial and immunoregulatory-immunostimulatory effects $[19,31,32]$. We have observed in an in vitro study previously published by our laboratory that raw curcumin had no antimicrobial effect against $S$. Enteritidis [33]. Additionally, it has been shown that curcumin supplementation promotes changes in the composition and diversity of the gut microbiome since the relative abundance of the Lactobacillus genus could be increased [34-36]. This increase in the abundance of Lactobacillus has a beneficial effect in suppressing the growth of pathogenic bacteria in the intestine of chickens [37] due to their different antimicrobial mechanisms [38,39], as well as, the maintenance of intestinal homeostasis. Although lactic acid bacteria were not determined in the present study, as shown in Table 2, only chickens treated with SD-CUR increased the total anaerobic bacteria counts $\left(0.31 \log _{10} \mathrm{cfu} / \mathrm{gr}, \mathrm{P}=0.07\right)$, which suggests an increase in the diversity of the microbiota that could be related to a higher activity against Salmonella.

Previous studies have demonstrated that Salmonella can disrupt intercellular junctions, causing an increase of paracellular permeability and bacterial translocation to facilitate its pathogenicity [40]. In this sense, a way to evaluate the intestinal integrity is the determination of the serum FITC-d levels, a molecule that under normal intestinal conditions does not cross the mucosal barrier due to its large size (3-5 kDa) [41,42]. The results showed that the group supplemented with SD-CUR presented significantly lower serum FITC-d levels $(0.159 \mu \mathrm{g} / \mathrm{mL})$ compared to the other experimental groups. Lower serum FITC-d levels are related to the maintenance of intestinal integrity due to the reduction of Salmonella counts and the ability of curcumin to restore the intestinal barrier function and expression of tight junction proteins, as well as the proliferation/regeneration of the intestinal epithelium $[35,43,44]$.

Mucosal immunity provides the first line of defense against oral exposure to pathogens, avoiding their adherence and invasion of epithelial cells [45]. Salmonella infection can induce a rapid and robust 
local inflammatory response in the intestinal epithelium, leading to the secretion of pro-inflammatory cytokines IL-1, IL-6, IL-23 IL-12, and IL-18, these last two lead to the production of interferon-gamma (IFN- $\gamma$ ) and tumor necrosis factor-alpha (TNF- $\alpha$ ) followed by the production of IgA and antimicrobial peptides (defensins, cathelicidins, histatins, and lactoferrins) as a defensive mechanism to limit the mucosal colonization of pathogens [45-49]. In both treatment groups, total intestinal IgA levels were significantly lower compared to the PC group (AA: $2.7 \mu \mathrm{g} / \mathrm{mL}$ and SD-CUR: $3.01 \mu \mathrm{g} / \mathrm{mL}$ ), which is consistent with the lower count of $S$. Enteritidis and their possible positive effects on the maintenance of intestinal integrity due also to their anti-inflammatory and antioxidant properties since it has been described that the production is not immediate $[45,50]$. It has been reported that curcumin does not only down-regulate pro-inflammatory cytokines to reduce local inflammation in the intestine, but also reduces systemic inflammation triggered by the release of lipopolysaccharide (LPS) into circulation [44,51,52]. Similar to curcumin, AA is capable of decreasing the expression of proinflammatory cytokines such as IL-1, IL-6, IL-12, TNF- $\alpha$ and IFN- $\gamma[53,54]$, which is indicative of better intestinal health.

The results obtained of total intestinal IgA levels in the AA and SD-CUR groups are also supported by the significant increase in the antioxidant activity of SOD compared to the PC group $(0.92$ and $0.90 \mathrm{U} / \mathrm{mL}$, respectively) since the increase in antioxidant capacity can lead to the reduction of oxidative stress and inflammation [9]. SOD is one of the most important antioxidant enzymes involved in the protection of tissues from oxidative damage by regulating various reactive oxygen and nitrogen species (ROS/RNS) [55]. However, the increase in SOD activity in the groups treated with AA and SD-CUR was due to their ability to stimulate the production of this antioxidant enzyme to protect the host against oxidative stress and lipid peroxidation [56-58].

Unlike the prophylactic model, in the therapeutic model, only the dietary administration of AA significantly decreased the counts and incidence of $S$. Enteritidis in both the crop and CT on days 3 and 10 post-S. Enteritidis challenge. These results are related to the acidifying capacity of AA in the crop $[23,24]$; whereby the concentration of $S$. Enteritidis that reached the intestinal epithelium was much lower. Furthermore, these results are supported by those previously published by our research group where AA was able to reduce the concentration of $S$. Enteritidis in the compartment that simulates the crop in an in vitro avian digestion model [33]. Although not significant either on days 3 and 10 post-S. Enteritidis challenge, $S$. Enteritidis counts in CT were reduced in chickens treated with SD-CUR by $1.59 \log$ and $1.80 \mathrm{log}$, respectively. This could be because the dose of SD-CUR was insufficient to exert a potent antimicrobial activity in this therapeutic model, which indicates that SD-CUR has a better effect in preventing $S$. Enteritidis infections/colonization. Despite these results, serum FITC-d levels were reduced by AA and SD-CUR treatments. In the SD-CUR treated group, the decrease in the serum FITC-d levels is due to the ability of curcumin to restore the intestinal barrier function and expression of tight junction proteins, resulting in a reduction of paracellular permeability [35,52]. Meanwhile, in the treatment with AA, the reduction of mucosal FITC-d permeability is mainly associated with the decrease in the severity of $S$. Enteritidis infection [59], which was also reflected in the lower total intestinal IgA levels compared to the SD-CUR and PC groups. However, the SD-CUR treated group had lower IgA values compared to the PC group, but not significantly. Finally, there were no significant differences in SOD activity among groups. The high activity of SOD in the treated groups is related to the capability of these two antioxidants to stimulate the production of antioxidant enzymes. However, the slight increase in SOD in the PC group was because this antioxidant enzyme protects the tissues from the oxidative damage of ROS/RNS, a defense mechanism against microbial invasion and replication [55]. 


\section{Materials and Methods}

\subsection{Preparation of Experimental Treatments and Diets}

Two treatments were evaluated: (1) AA (99\%-100\%, Food grade, Drogueria Cosmopolitan, Naucalpan, Edo. de Mex., Mexico); and (2) a solid dispersion of curcumin (SD-CUR). The first treatment was prepared by granulating 90\% AA with 10\% microcrystalline cellulose (MCC, Avicel@PH 102), followed by a drying step and subsequent sieving. Treatment 2 was prepared by dissolving 1 part of curcumin in 9 parts of a polyvinylpyrrolidone (PVP) K30 solution, followed by water evaporation at $40{ }^{\circ} \mathrm{C}$ and sieving. In both treatments, the sieving was done using a No. 25 mesh to obtain particles of around $700 \mu \mathrm{m}$. These treatments were included in starter basal diets without antibiotics, coccidiostats, or enzymes at a concentration of $0.1 \%$ ( $1 \mathrm{~kg} /$ Ton of feed). A starter diet was formulated to approximate the nutritional requirements of broiler chickens as recommended by the National Research Council [60] and adjusted to breeder's recommendations [61]. All animal handling procedures complied with the Institutional Animal Care and Use Committee (IACUC) at the University of Arkansas, Fayetteville (protocol \#18029).

\subsection{Salmonella Strain and Culture Conditions}

A primary poultry isolate of Salmonella enterica serovar Enteritidis bacteriophage type 13A, was obtained from the USDA National Veterinary Services Laboratory (Ames, IA, USA). This strain is resistant to $25 \mu \mathrm{g} / \mathrm{mL}$ of novobiocin (NO, catalog no. N-1628, Sigma) and was selected due to its resistance to $20 \mu \mathrm{g} / \mathrm{mL}$ of nalidixic acid (NA, catalog no. N-4382, Sigma) in our laboratory. The Salmonella Enteritidis culture was performed according to previous publications [19] to obtain approximate bacterial concentrations of $4 \times 10^{4}$ and $4 \times 10^{7} \mathrm{cfu} / \mathrm{mL}$. Levels of $S$. Enteritidis were further verified by serial dilutions and plated on brilliant green agar (BGA, Catalog No. 70134, Sigma) with NO and NA for enumeration of actual cfu used in the experiment.

\subsection{Experimental Design}

Two experiments were conducted to evaluate the effect of AA and SD-CUR at $0.1 \%$ in the feed in a prophylactic or therapeutic model against $S$. Enteritidis infection and their influence on intestinal integrity in broiler chickens.

\subsubsection{Prophylactic Model}

The prophylactic model consisted of two independent trials with 45 day-of-hatch Cobb-Vantress male broiler chickens (Fayetteville, AR, USA) each. In both trials, chickens were randomly assigned to one of three groups ( $n=15$ chickens/group): (1) positive control group (PC), (2) $0.1 \%$ AA in the feed, and (3) $0.1 \%$ SD-CUR in the feed. Chicks were housed in brooder battery cages, provided with their respective diet and water ad libitum, as well as maintained at an age-appropriate temperature during the experiment. On day 6 of age, all chicks were orally challenged with $1 \times 107 \mathrm{cfu}$ of $\mathrm{S}$. Enteritidis per bird and weighed to calculate the concentration of fluorescein isothiocyanate-dextran (FITC-d) to be administered according to the group body weight (only trial 2). Subsequently, 24 h post-S. Enteritidis challenge (7 day-old), chicks were euthanized by $\mathrm{CO} 2$ inhalation, and samples of crop and cecal tonsils (CT) for S. Enteritidis colony counts from 12 broilers per group were collected (both independent trials). Additionally, only in trial 2, blood samples from the femoral vein for determination of FITC-d and superoxide dismutase (SOD) as described below, as well as samples of CT for total aerobic bacteria (TAB) colony counts and intestinal samples for total intestinal IgA levels ( $\mathrm{n}=12 /$ group) were also collected. 


\subsubsection{Therapeutic Model}

To evaluate this model, 90 one-day-old Cobb-Vantress male broiler chickens (Fayetteville, AR, USA) were challenged with $1 \times 10^{4} \mathrm{cfu}$ of $S$. Enteritidis per bird at day of hatch and randomly allocated to one of three groups ( $\mathrm{n}=30$ chickens): (1) positive control group (PC); (2) $0.1 \%$ AA in the feed; and (3) $0.1 \%$ SD-CUR in the feed. Chicks were housed in brooder battery cages, provided with their respective diet and water ad libitum, as well as maintained at an age-appropriate temperature during the experiment. On days 3 and 10 post-S. Enteritidis challenge, 15 chicks from each group were euthanized by $\mathrm{CO}_{2}$ inhalation, respectively, but only the crop and CT from 12 birds per group were aseptically collected for $S$. Enteritidis count. Blood samples were also collected from the femoral vein for the determination of FITC-d and SOD, only on day 10 post-S. Enteritidis challenge. The concentration of FITC-d administered was calculated based on group body weight at day 9 post-S. Enteritidis challenge. Furthermore, intestinal samples for total intestinal IgA levels were also collected at day 10 post-challenge.

\subsection{Salmonella and Total Aerobic Bacteria (TAB) Counts}

In both experimental models, the crop and CT samples from 12 chickens per group were homogenized and diluted with saline (1:4 w/v), and 10-fold dilutions were plated on BGA with NO and NA for S. Enteritidis counts or on Tryptic Soy Agar (TSA, catalog no. 211822, Becton Dickinson, Sparks, MD) for TAB determination (only in the prophylactic model, trial 2). Plates were incubated at $37^{\circ} \mathrm{C}$ for $24 \mathrm{~h}$ to enumerate total $\mathrm{S}$. Enteritidis and TAB colony-forming units. Subsequently, the crop and CT samples were enriched in $2 \times$ concentrated tetrathionate enrichment broth and further incubated at $37^{\circ} \mathrm{C}$ for $24 \mathrm{~h}$. Enrichment samples were streaked onto Xylose Lysine Tergitol-4 (XLT-4, Catalog No. 223410, BD Difco ${ }^{\mathrm{TM}}$ ) selective media for confirmation of Salmonella incidence.

\subsection{Serum FITC-d Levels}

FITC-d (MW 3-5 kDa; Sigma-Aldrich Co., St. Louis, MO, USA) was provided by oral gavage to 12 broiler chickens from each group at a dose of $8.32 \mathrm{mg} / \mathrm{kg}$ of body weight one hour before the chicks were euthanized by $\mathrm{CO}_{2}$ inhalation in order to collect blood samples and evaluate the paracellular transport and mucosal barrier dysfunction [62,63]. Three remaining broiler chickens of each group were used as controls. The blood samples were centrifuged $(1000 \times g$ for $15 \mathrm{~min})$ to separate the serum. Then, serum samples obtained were diluted (1:5) and measured fluorometrically at an excitation wavelength of $485 \mathrm{~nm}$ and an emission wavelength of $528 \mathrm{~nm}$ (Synergy HT, Multi-mode microplate reader, BioTek Instruments, Inc., VT, USA) to determine the serum FITC-d levels [41].

\subsection{Superoxide Dismutase Activity}

Superoxide dismutase (SOD) activity was measured in serum samples from 12 chickens using a commercial assay kit in each experimental model (Cayman chemical company, Item No. 706002, Ann Arbor, MI, USA) following the manufacturer's instructions. Three types of SOD (Cu/Zn, Mn, and FeSOD) were determined, and the optimal dilution to quantify the SOD activity was 1:5. Samples were measured at $450 \mathrm{~nm}$ using an ELISA plate reader (Synergy HT, multi-mode microplate reader, BioTek Instruments, Inc., Winooski, VT, USA).

\subsection{Total Intestinal Immunoglobulin A (IgA) Levels}

In each experimental model, intestinal sections of $5 \mathrm{~cm}$ from the Meckel's diverticulum to the ileocecal junction from 12 chickens per group were taken to quantify total IgA levels [64]. Briefly, intestinal sections were rinsed three times with $5 \mathrm{~mL}$ of $0.9 \%$ saline; then the rinse was collected in a tube and centrifuged at $1864 \times g$ at $4{ }^{\circ} \mathrm{C}$ for $10 \mathrm{~min}$. Subsequently, the supernatants were separated and stored at $-20^{\circ} \mathrm{C}$ until tested. A commercial indirect ELISA kit was used to quantify IgA according to the manufacturer's instructions (Catalog No. E30-103, Bethyl Laboratories Inc., Montgomery, TX 
77356, USA). The intestinal rinse supernatants were diluted (1:100), placed in 96-well plates (Catalog No. 439454, Nunc MaxiSorp, Thermo Fisher Scientific, Rochester, NY, USA), and measured at $450 \mathrm{~nm}$ using an ELISA plate reader (Synergy HT, multi-mode microplate reader, BioTek Instruments, Inc., Winooski, VT, USA).

\subsection{Data and Statistical Analysis}

Data from $S$. Enteritidis and TAB counts (log cfu/g), serum FITC-d levels, total intestinal IgA levels, and SOD activity were subjected to analysis of variance (ANOVA) as a completely randomized design using the General Linear Models procedure of Statistical Analysis System (SAS®) [65]. Significant differences among the means were determined by Duncan's multiple range test at $\mathrm{P}<0.05$. Enrichment data were expressed as positive/total chickens (\%), and the percentage of $S$. Enteritidis positive samples were compared by a chi-squared test of independence [66], testing all possible combinations to determine the significance $(\mathrm{P}<0.05)$.

\section{Conclusions}

The inclusion of AA and SD-CUR in the diet can be an alternative for the production of antibiotic-free poultry to reduce bacterial antimicrobial resistance problems and maintain food safety that is extremely important in public health concern. The results suggest that dietary AA or SD-CUR have different modes of action to reduce SE intestinal colonization in two different challenge models in broiler chickens. Further studies to confirm these results and using higher concentrations of these additives are currently being evaluated.

Author Contributions: D.H.-P., B.S.-C., and G.T.-I., contributed to the overall study design and supervised all research. K.P.P., J.D.L., carried out the experiments. D.H.-P., G.T.-I., X.H.-V., R.M.-G., A.M.-A., analyzed the data and drafted and revised the first version of the manuscript. D.H.-P., B.S.-C., prepared the tables. B.M.H., R.L.-A., G.T.-I., investigation, analyzed the data, and were also responsible for the final editing of the manuscript. All the authors reviewed, edited, and approved the manuscript.

Funding: This research received no external funding.

Acknowledgments: This research was supported by the Arkansas Bioscience Institute under the project: Development of an avian model for evaluation early enteric microbial colonization on the gastrointestinal tract and immune function. The authors thank the CONACyT for the doctoral grant number 270728.

Conflicts of Interest: The authors declare that the research was conducted in the absence of any commercial or financial relationships that could be construed as a potential conflict of interest.

\section{References}

1. Nair, D.V.T.; Venkitanarayanan, K.; Johny, A.K. Antibiotic-Resistant Salmonella in the Food Supply and the Potential Role of Antibiotic Alternatives for Control. Foods 2018, 7, 167. [CrossRef]

2. Cheng, G.; Hao, H.; Xie, S.; Wang, X.; Dai, M.; Huang, L.; Yuan, Z. Antibiotic alternatives: The substitution of antibiotics in animal husbandry? Front. Microbiol. 2014, 5, 217. [CrossRef]

3. Hao, H.; Cheng, G.; Iqbal, Z.; Ai, X.; Hussain, H.I.; Huang, L.; Dai, M.; Wang, Y.; Liu, Z.; Yuan, Z. Benefits and risks of antimicrobial use in food-producing animals. Front. Microbiol. 2014, 5, 288. [CrossRef] [PubMed]

4. Marshall, B.M.; Levy, S.B. Food Animals and Antimicrobials: Impacts on Human Health. Clin. Microbiol. Rev. 2011, 24, 718-733. [CrossRef] [PubMed]

5. Borck Høg, B.; Korsgaard, H.B.; Wolff Sönksen, U.; Bager, F.; Bortolaia, V.; Ellis-Iversen, J.; Hendriksen, R.S.; Borck Høg, B.; Jensen, L.B.; Korsgaard, H.B.; et al. DANMAP 2016-Use of Antimicrobial Agents and Occurrence of Antimicrobial Resistance in Bacteria from Food Animals, Food and Humans in Denmark; Statens Serum Institut, National Veterinary Institute, Technical University of Denmark National Food Institute: Lyngby, Denmark, 2017. Available online: https://orbit.dtu.dk/files/140535625/DANMAP_2016_LOW_241017.pdf (accessed on 10 August 2019).

6. Founou, L.L.; Founou, R.C.; Essack, S.Y. Antibiotic Resistance in the Food Chain: A Developing Country-Perspective. Front. Microbiol. 2016, 7, 1881. [CrossRef] [PubMed] 
7. Lillehoj, H.; Liu, Y.; Calsamiglia, S.; Fernandez-Miyakawa, M.E.; Chi, F.; Cravens, R.L.; Oh, S.; Gay, C.G. Phytochemicals as antibiotic alternatives to promote growth and enhance host health. Vet. Res. 2018, $49,76$. [CrossRef] [PubMed]

8. WHO Salmonella (Non-Typhoidal). 2018. Available online: https://www.who.int/es/news-room/fact-sheets/ detail/salmonella-(non-typhoidal) (accessed on 12 August 2019).

9. Johannah, N.M.; Joseph, A.; Maliakel, B.; Krishnakumar, I.M. Dietary addition of a standardized extract of turmeric (TurmaFEED TM) improves growth performance and carcass quality of broilers. J. Anim. Sci. Technol. 2018, 60, 8.

10. Luna, A.; Lema-Alba, R.C.; Dambolena, J.S.; Zygadlo, J.A.; Labaque, M.C.; Marin, R.H. Thymol as natural antioxidant additive for poultry feed: Oxidative stability improvement. Poult. Sci. 2017, 96, 3214-3220. [CrossRef]

11. Surai, P.F. Natural Antioxidants in Poultry Nutrition: New Developments. In Proceedings of the 16th European Symposium on Poultry Nutrition, World Poultry Science Association, Strasbourg, France, 26-30 August 2007.

12. Chakraborthy, A.; Ramani, P.; Sherlin, H.; Premkumar, P.; Natesan, A. Antioxidant and pro-oxidant activity of Vitamin C in oral environment. Indian J. Dent. Res. 2014, 25, 499. [CrossRef]

13. Carr, A.; Maggini, S. Vitamin C and immune function. Nutrients 2017, 9, 1211. [CrossRef]

14. Traber, M.G.; Buettner, G.R.; Bruno, R.S. The relationship between vitamin C status, the gut-liver axis, and metabolic syndrome. Redox Biol. 2018, 21, 101091. [CrossRef] [PubMed]

15. Lohakare, J.D.; Lee, J.K.; Chae, B.J.; Ryu, M.H.; Hahn, T.-W. Effects of Supplemental Ascorbic Acid on the Performance and Immunity of Commercial Broilers. J. Appl. Poult. Res. 2005, 14, 10-19. [CrossRef]

16. Malik, P.; Mukherjee, T.K. Structure-Function Elucidation of Antioxidative and Prooxidative Activities of the Polyphenolic Compound Curcumin. Chin. J. Biol. 2014, 2014, 396708. [CrossRef]

17. Khan, R.; Naz, S.; Javdani, M.; Nikousefat, Z.; Selvaggi, M.; Tufarelli, V.; Laudadio, V. The use of Turmeric (Curcuma longa) in poultry feed. World Poult. Sci. J. 2012, 68, 97-103. [CrossRef]

18. Ramos, L.; Paredes, J.C.Z.; Moreno, C.; Ruales, P.; Guil-Guerrero, J.L.; Carlosama-Yépez, M. Effects of turmeric rhizome powder and curcumin in poultry production. A review. J. Anim. Feed. Sci. 2017, 26, 293-302.

19. Hernández-Patlán, D.; Solís-Cruz, B.; Pontin, K.P.; Latorre, J.D.; Baxter, M.F.A.; Hérnandez-Velasco, X.; Merino-Guzmán, R.; Méndez-Albores, A.; Hargis, B.M.; López-Arellano, R.; et al. Evaluation of a Solid Dispersion of Curcumin with Polyvinylpyrrolidone and Boric Acid Against Salmonella Enteritidis Infection and Intestinal Permeability in Broiler Chickens: A Pilot Study. Front. Microbiol. 2018, 9, 1289. [CrossRef] [PubMed]

20. Paolino, D.; Vero, A.; Cosco, D.; Pecora, T.M.G.; Cianciolo, S.; Fresta, M.; Pignatello, R. Improvement of Oral Bioavailability of Curcumin upon Microencapsulation with Methacrylic Copolymers. Front. Pharmacol. 2016, 7, 485. [CrossRef]

21. Tran, K.A.; Tran, T.T.D.; Van Vo, T.; Van Tran, T.; Tran, P.H.L. Investigation of Solid Dispersion Methods to Improve the Dissolution Rate of Curcumin. In Proceedings of the 5th International Conference on Biomedical Engineering in Vietnam, Ho Chi Minh, Vietnam, 16-18 June 2014; Van Toi, V., Lien Phuong, T.H., Eds.; Springer: Berlin/Heidelberg, Germany, 2015; pp. 293-297.

22. Cervantes, H.M. Antibiotic-free poultry production: Is it sustainable? J. Appl. Poult. Res. 2015, $24,91-97$. [CrossRef]

23. Mani-López, E.; Garcia, H.; López-Malo, A. Organic acids as antimicrobials to control Salmonella in meat and poultry products. Food Res. Int. 2012, 45, 713-721. [CrossRef]

24. Mathew, S.; Verghese, R.; David, A. Antimicrobial activity of Vitamin C demonstrated on uropathogenic Escherichia coli and Klebsiella pneumoniae. J. Curr. Res. Sci. Med. 2017, 3, 88-93. [CrossRef]

25. Wechtersbach, L.; Cigić, B. Reduction of dehydroascorbic acid at low pH. J. Biochem. Biophys. Methods 2007, 70, 767-772. [CrossRef] [PubMed]

26. Akın, M.B.; Dasnik, F. Effects of ascorbic acid and glucose oxidase levels on the viability of probiotic bacteria and the physical and sensory characteristics in symbiotic ice-cream. Mljekarstvo 2015, 65, 121-129. [CrossRef]

27. Brown, D.R.; Southern, L.L. Effect of Citric and Ascorbic Acids on Performance and Intestinal pH of Chicks. Poult. Sci. 1985, 64, 1399-1401. [CrossRef] [PubMed] 
28. Marín-Flamand, E.; Vazquez-Duran, A.; Méndez-Albores, A. Effect of Organic Acid Blends in Drinking Water on Growth Performance, Blood Constituents and Immune Response of Broiler Chickens. J. Poult. Sci. 2014, 51, 144-150. [CrossRef]

29. Xu, D.H.; Wang, S.; Jin, J.; Mei, X.T.; Xu, S.B. Dissolution and absorption researches of curcumin in solid dispersions with the polymers PVP. Asian J. Pharmacodyn. Pharmacokinet. 2006, 6, 343-349.

30. Zhang, Q.; Polyakov, N.E.; Chistyachenko, Y.S.; Khvostov, M.V.; Frolova, T.S.; Tolstikova, T.G.; Dushkin, A.V.; $\mathrm{Su}, \mathrm{W}$. Preparation of curcumin self-micelle solid dispersion with enhanced bioavailability and cytotoxic activity by mechanochemistry. Drug Deliv. 2018, 25, 198-209. [CrossRef] [PubMed]

31. Moghadamtousi, S.Z.; Kadir, H.A.; Hassandarvish, P.; Tajik, H.; Abubakar, S.; Zandi, K. A Review on Antibacterial, Antiviral, and Antifungal Activity of Curcumin. BioMed Res. Int. 2014, 2014, 186864.

32. Catanzaro, M.; Corsini, E.; Rosini, M.; Racchi, M.; Lanni, C. Immunomodulators Inspired by Nature: A Review on Curcumin and Echinacea. Molecules 2018, 23, 2778. [CrossRef]

33. Hernandez-Patlan, D.; Solis-Cruz, B.; Méndez-Albores, A.; Latorre, J.D.; Hernandez-Velasco, X.; Tellez, G.; López-Arellano, R. Comparison of PrestoBlueßand plating method to evaluate antimicrobial activity of ascorbic acid, boric acid and curcumin in an in vitro gastrointestinal model. J. Appl. Microbiol. 2018, 124, 423-430. [CrossRef]

34. Varmuzova, K.; Matulova, M.E.; Gerzova, L.; Cejkova, D.; Gardan-Salmon, D.; Panhéleux, M.; Robert, F.; Sisak, F.; Havlickova, H.; Rychlik, I. Curcuma and Scutellaria plant extracts protect chickens against inflammation and Salmonella Enteritidis infection. Poult. Sci. 2015, 94, 2049-2058. [CrossRef]

35. Peterson, C.T.; Vaughn, A.R.; Sharma, V.; Chopra, D.; Mills, P.J.; Peterson, S.N.; Sivamani, R.K. Effects of Turmeric and Curcumin Dietary Supplementation on Human Gut Microbiota: A Double-Blind, Randomized, Placebo-Controlled Pilot Study. J. Evid. Based Integr. Med. 2018, 23. [CrossRef] [PubMed]

36. Vamanu, E.; Gatea, F.; Sârbu, I.; Pelinescu, D. An In Vitro Study of the Influence of Curcuma longa Extracts on the Microbiota Modulation Process, In Patients with Hypertension. Pharmaceutics 2019, 11, 191. [CrossRef] [PubMed]

37. Samarasinghe, K.; Wenk, C.; Silva, K.F.S.T.; Gunasekera, J.M.D.M. Turmeric (Curcuma longa) Root Powder and Mannanoligosaccharides as Alternatives to Antibiotics in Broiler Chicken Diets. Asian Australas. J. Anim. Sci. 2003, 16, 1495-1500. [CrossRef]

38. Alagawany, M.; El-Hack, M.E.A.; Farag, M.R.; Sachan, S.; Karthik, K.; Dhama, K. The use of probiotics as eco-friendly alternatives for antibiotics in poultry nutrition. Environ. Sci. Pollut. Res. 2018, 25, 10611-10618. [CrossRef]

39. Vieco-Saiz, N.; Belguesmia, Y.; Raspoet, R.; Auclair, E.; Gancel, F.; Kempf, I.; Drider, D. Benefits and Inputs From Lactic Acid Bacteria and Their Bacteriocins as Alternatives to Antibiotic Growth Promoters During Food-Animal Production. Front. Microbiol. 2019, 10, 57. [CrossRef]

40. Brufau, M.T.; Campo-Sabariz, J.; Bou, R.; Carné, S.; Brufau, J.; Vilà, B.; Marqués, A.M.; Guardiola, F.; Ferrer, R.; Martin-Venegas, R. Salmosan, a $\beta$-Galactomannan-Rich Product, Protects Epithelial Barrier Function in Caco-2 Cells Infected by Salmonella enterica Serovar Enteritidis. J. Nutr. 2016, 146, 1492-1498. [CrossRef]

41. Baxter, M.F.A.; Merino-Guzman, R.; Latorre, J.D.; Mahaffey, B.D.; Yang, Y.; Teague, K.D.; Graham, L.E.; Wolfenden, A.D.; Hernandez-Velasco, X.; Bielke, L.R.; et al. Optimizing Fluorescein Isothiocyanate Dextran Measurement As a Biomarker in a 24-h Feed Restriction Model to Induce Gut Permeability in Broiler Chickens. Front. Vet. Sci. 2017, 4, 56. [CrossRef]

42. Tellez, G.; Latorre, J.D.; Kuttappan, V.A.; Kogut, M.H.; Wolfenden, A.; Hernandez-Velasco, X.; Hargis, B.M.; Bottje, W.G.; Bielke, L.R.; Faulkner, O.B. Utilization of rye as energy source affects bacterial translocation, intestinal viscosity, microbiota composition, and bone mineralization in broiler chickens. Front. Genet. 2014, 5, 339. [CrossRef]

43. Bereswill, S.; Muñoz, M.; Fischer, A.; Plickert, R.; Haag, L.-M.; Otto, B.; Kühl, A.A.; Loddenkemper, C.; Göbel, U.B.; Heimesaat, M.M. Anti-Inflammatory Effects of Resveratrol, Curcumin and Simvastatin in Acute Small Intestinal Inflammation. PLoS ONE 2010, 5, e15099. [CrossRef]

44. Wang, J.; Ghosh, S.S.; Ghosh, S. Curcumin improves intestinal barrier function: Modulation of intracellular signaling, and organization of tight junctions. Am. J. Physiol. Physiol. 2017, 312, C438-C445. [CrossRef]

45. Sheela, R.R.; Babu, U.; Mu, J.; Elankumaran, S.; Bautista, D.A.; Raybourne, R.B.; Heckert, R.A.; Song, W. Immune Responses against Salmonella enterica Serovar Enteritidis Infection in Virally Immunosuppressed Chickens. Clin. Diagn. Lab. Immunol. 2003, 10, 670-679. [CrossRef] [PubMed] 
46. Kogut, M.H. Cytokines and prevention of infectious diseases in poultry: A review. Avian Pathol. 2000, 29, 395-404. [CrossRef] [PubMed]

47. Fasina, Y.O.; Moore, R.W.; Holt, P.S.; Moran, E.T.; Conner, D.E.; McKee, S.R. Intestinal Cytokine Response of Commercial Source Broiler Chicks to Salmonella Typhimurium Infection. Poult. Sci. 2008, 87, 1335-1346. [CrossRef] [PubMed]

48. Park, S.H.; Biswas, D.; Lingbeck, J.; Koo, O.K.; Ricke, S.C. Enhancement of chicken macrophage cytokine response toSalmonellaTyphimurium when combined with bacteriophage P22. FEMS Microbiol. Lett. 2013, 339, 137-144. [CrossRef]

49. Patel, S.; McCormick, B.A. Mucosal Inflammatory Response to Salmonella typhimurium Infection. Front. Immunol. 2014, 5, 311. [CrossRef]

50. Filho, R.A.C.P.; Moura, B.S.; De Almeida, A.M.; Montassier, H.J.; Barrow, P.A.; Júnior, A.B. Humoral and cellular immune response generated by different vaccine programs before and after Salmonella Enteritidis challenge in chickens. Vaccine 2012, 30, 7637-7643. [CrossRef]

51. Gupta, S.C.; Patchva, S.; Koh, W.; Aggarwal, B.B. Discovery of curcumin, a component of golden spice, and its miraculous biological activities. Clin. Exp. Pharmacol. Physiol. 2012, 39, 283-299. [CrossRef]

52. Ghosh, S.S.; He, H.; Wang, J.; Gehr, T.W.; Ghosh, S. Curcumin-mediated regulation of intestinal barrier function: The mechanism underlying its beneficial effects. Tissue Barriers 2018, 6, e1425085. [CrossRef]

53. Kong, E.H.; Ma, S.Y.; Jeong, J.Y.; Kim, K.H. Effects of L-ascorbic acid on the production of pro-inflammatory and anti-inflammatory cytokines in C57BL/6 mouse splenocytes. Kosin Med. J. 2015, 30, 41-49. [CrossRef]

54. El-Senousey, H.K.; Chen, B.; Wang, J.Y.; Atta, A.M.; Mohamed, F.R.; Nie, Q.H. Effects of dietary vitamin C, vitamin $\mathrm{E}$, and alpha-lipoic acid supplementation on the antioxidant defense system and immune-related gene expression in broilers exposed to oxidative stress by dexamethasone. Poult. Sci. 2017, 97, 30-38. [CrossRef]

55. Break, T.J.; Jun, S.; Indramohan, M.; Carr, K.D.; Sieve, A.N.; Dory, L.; Berg, R.E. Extracellular superoxide dismutase inhibits innate immune responses and clearance of an intracellular bacterial infection. J. Immunol. 2012, 188, 3342-3350. [CrossRef] [PubMed]

56. Ismail, I.; Al-Busadah, K.; El-Bahr, S. Oxidative Stress Biomarkers and Biochemical Profile in Broilers Chicken Fed Zinc Bacitracin and Ascorbic Acid under Hot Climate. Am. J. Biochem. Mol. Biol. 2013, 3, 202-214.

57. Al-Rubaei, Z.M.; Mohammad, T.U.; Ali, L.K. Effects of local curcumin on oxidative stress and total antioxidant capacity in vivo study. Pak. J. Biol. Sci. 2014, 17, 1237-1241. [CrossRef] [PubMed]

58. Hu, R.; He, Y.; Arowolo, M.A.; Wu, S.; He, J. Polyphenols as Potential Attenuators of Heat Stress in Poultry Production. Antioxidants 2019, 8, 67. [CrossRef]

59. Wigley, P. Salmonella enterica in the Chicken: How it has Helped Our Understanding of Immunology in a Non-Biomedical Model Species. Front. Immunol. 2014, 5, 482. [CrossRef]

60. National Research Council. Nutrient Requirements of Poultry, 9th ed.; National Academy Press: Washington, DC, USA, 1994; pp. 19-34.

61. Cobb-Vantress, I. Cobb 500 Broiler Performance and Nutrition Supplement. 2015. Available online: https://www.cobb-vantress.com/assets/Cobb-Files/product-guides/bdc20a5443/70dec630-0abf-11e99c88-c51e407c53ab.pdf (accessed on 9 November 2019).

62. Vicuña, E.A.; Kuttappan, V.A.; Galarza-Seeber, R.; Latorre, J.D.; Faulkner, O.B.; Hargis, B.M.; Tellez, G.; Bielke, L.R. Effect of dexamethasone in feed on intestinal permeability, differential white blood cell counts, and immune organs in broiler chicks. Poult. Sci. 2015, 94, 2075-2080. [CrossRef]

63. Vicuña, E.A.; Kuttappan, V.A.; Tellez, G.; Hernandez-Velasco, X.; Seeber-Galarza, R.; Latorre, J.D.; Faulkner, O.B.; Wolfenden, A.D.; Hargis, B.M.; Bielke, L.R. Dose titration of FITC-D for optimal measurement of enteric inflammation in broiler chicks. Poult. Sci. 2015, 94, 1353-1359. [CrossRef]

64. Merino-Guzmán, R.; Latorre, J.D.; Delgado, R.; Hernandez-Velasco, X.; Wolfenden, A.D.; Teague, K.D.; Graham, L.E.; Mahaffey, B.D.; Baxter, M.F.A.; Hargis, B.M.; et al. Comparison of total immunoglobulin A levels in different samples in Leghorn and broiler chickens. Asian Pac. J. Trop. Biomed. 2017, 7, 116-120. [CrossRef] 
65. SAS Institute Inc. SAS/Share: 9.4 User's Guide, 2nd ed.; SAS Documentation: Cary, NC, USA, 2002.

66. Zar, J.H. Biostatistical Analysis, 2nd ed.; Prentice Hall: Englewood Cliffs, NJ, USA, 1984; p. 718.

(C) 2019 by the authors. Licensee MDPI, Basel, Switzerland. This article is an open access article distributed under the terms and conditions of the Creative Commons Attribution (CC BY) license (http://creativecommons.org/licenses/by/4.0/). 